\title{
WILLIAM BLAKE E AS VOZES PROFÉTICAS DA TRADIÇÃO DISSIDENTE ${ }^{1}$
}

\section{WILLIAM BLAKE AND THE PROPHETIC VOICES OF DISSIDENT TRADITION}

Juliana Steil

Universidade Federal de Pelotas Pelotas, Rio Grande do Sul, Brasil

Resumo: Em Fearful Symmetry, Frye menciona a necessidade de desfazer o "mito de que Blake é uma anomalia literária" (FRYE, 1990, p. 147). Considerando que persistem ressonâncias deste mito, este artigo explora a afinidade entre a obra poética de William Blake e a tradição dissidente inglesa, uma relação raramente discutida pela crítica do poeta no Brasil. O artigo revisa a literatura existente sobre o assunto e, destacando os trabalhos de Mee $(1992,1994,2003)$ e de Makdisi (2003), avalia a inclinação antinomiana dos escritos de Blake para explicar as ideias de "profeta" e de "profecia" assumidas em seus poemas proféticos.

Palavras-chave: William Blake; Poesia profética; Tradição dissidente; Radicalismo

\begin{abstract}
In Fearful Symmetry, Frye comments on the need to undo the "myth that Blake is a literary freak" (FRYE, 1990, p. 147). On the assumption that there continue to be resonances from this myth, this paper looks at the affinity between William Blake's poetic work and the dissident English tradition, a relationship that is rarely discussed by experts on the poet in Brazil. The paper reviews the existing literature on the subject and, via the work of Mee $(1992,1994,2003)$ and Makdisi (2003), it assesses the antinomian angle of Blake's writings in order to explain the assumed ideas of "prophet" and "prophecy" in his prophetic poems.
\end{abstract}

Keywords: William Blake; Prophetic poetry; Dissident tradition; Radicalism

\footnotetext{
${ }^{1}$ A primeira versão deste texto foi apresentada na tese Tradução comentada de Milton, de William Blake (STEIL, 2011). Meu agradecimento a Juliet Attwater pela tradução do Resumo deste artigo para o inglês.

O presente trabalho foi realizado com apoio da Coordenação de Aperfeiçoamento de Pessoal de Nível Superior - Brasil (CAPES).
} 
A lei de pedra ao pó reduzo ${ }^{2}$

A fama de poeta excêntrico atribuída a William Blake (1757-1827), para além da inegável originalidade de sua obra, deve-se, em parte importante, à dificuldade de situá-la entre discursos ideológicos predominantes de seu tempo. Seus livros proféticos mostram afinidade, na verdade, com discursos radicais que alcançaram menor visibilidade no registro da história. Nesse sentido, é preciso lembrar que a oposição radical durante a sua época não se resumia ao grupo de Thomas Paine ${ }^{3}$; ao contrário, várias correntes ideológicas coexistiam (MEE, 1992, 2003; MAKDISI, 2003). Mais que isso, a produção artística de Blake encontra precedentes em um contexto já bastante diverso do século anterior. Nesse sentido, para verificar a inserção de Blake na tradição literária, é útil considerar que o poeta nasceu em uma família dissidente, que estudava a Bíblia em casa, embora não se saiba exatamente qual credo seguia (BENTLEY, 2001). Ainda assim, é possível identificar na obra do poeta a forte interferência de uma tradição que encontra raízes no ambiente das seitas radicais e igrejas dissidentes do século XVII, e até mesmo justificar, ao menos em parte, o seu estilo pouco adequado aos padrões literários de seu tempo.

A divisão e a pluralidade são fortes características no cenário dissidente da Inglaterra pós-reformista. Michael Mullett (1994) comenta que o Ato AntiSeparatista de 1593, que apoiava a perseguição e a execução dos dissidentes, não pôde conter o desenvolvimento de grupos e seitas formados por fiéis descontentes com a religião oficial, muitos deles encontrando no exílio a solução para a prática de seu credo em liberdade. Entre as tendências de origem erudita, Francis Johnson, educado em Cambridge, foi um dos mais importantes líderes do início do separatismo inglês, tornando-se pastor de um grupo de seguidores de Henry Barrow (pensador dissidente executado em 1593) na Holanda. Também na Holanda, John Smyth começou a pregar ideias ultrarradicais que defendiam "a eliminação virtual de um pastorado eclesiástico separado; uma abordagem de culto totalmente espiritual, espontânea e independente de livros; e uma definição pura e precisa de participação na igreja",4 (MULLETT, 1994, p. 191). A partir dos grupos formados no exílio, por sua vez, novos grupos dissidentes surgiram na Inglaterra. $\mathrm{O}$ pensamento religioso de Smyth, por exemplo, voltado para a

\footnotetext{
2 "That stony law I stamp to dust: (...)" (America, ERDMAN, 1988, p. 10). As traduções de citações cujos originais estão indicados em notas de rodapé são da autora do trabalho.

${ }^{3}$ Alguns críticos têm discutido a aproximação da obra de Blake com o pensamento do grupo de Paine. Para Saree Makdisi, por exemplo, uma das divergências entre a posição de Blake e a de Paine no contexto das revoluções está no conceito de liberdade (ver MAKDISI, 2003, p. 314).

4 " (....) the virtual elimination of a separate clerical pastorate; an entirely spiritual, spontaneous, bookless approach to worship; and a pure and restricted definition of church membership". As traduções das citações cujos originais estão indicados em notas de rodapé são da autora do artigo.
} 
adoração individual e o ato do rebatismo (SMITH, 1989, p. 04) provocou dois tipos de reações: apoio e identificação, dando origem aos batistas; uma resposta de tipo conservador, que resultou na organização de uma posição de "semiseparatismo", mais tarde dividindo-se com o aparecimento dos "batistas particulares" (MULLETT, 1994, pp. 192-193).

Mullett (1994) conta que, entre as correntes da vertente leiga, membros da classe dos comerciantes e artesãos passaram a assumir lideranças por volta de 1630, quando as atitudes austeras de Laud no reinado de Charles I, vistas como uma tentativa de retorno em direção do catolicismo, ajudaram a produzir um clima de antiacademicismo nas igrejas marginais, o que colaboraria para o surgimento do movimento em favor da democracia política na década de 1640 . Para Mullett (1994, p. 194), a principal contribuição da postura dissidente nessa época estava relacionada à teoria da Igreja em si, a busca de uma Igreja a ser aperfeiçoada a partir do modelo do Novo Testamento, livre do controle do Estado, baseada na aceitação voluntária e feita de "santos visíveis".

Contra este pluralismo religioso, escreve Mullett, entrou em cena, logo após o início da Guerra Civil em 1642, uma frente presbiteriana escocesa a favor da unificação religiosa na Grã-Bretanha, que exigiu apoio do Parlamento em troca de seu apoio na Guerra Civil. No entanto, para além dos vários grupos contrários a essa ideia, o plano de transformar a Inglaterra em uma "das melhores igrejas reformadas" encontrou resistência dentro da própria opinião puritana, que já se tornara vastamente heterogênea neste período. Uma oposição especial veio da parte dos "independentes", que defendiam uma identidade da congregação individual dentro da Igreja dominante e a necessidade de alguma liberdade de crenças. Os independentes, que, se não eram muito numerosos, abrigavam uma grande variedade de seitas, representaram a verdadeira ameaça radical no período de 1640-50: "Os brawnistas, anabatistas, arianos, thraskistas, familistas, sensualistas, antinomianos, e outros (...) eram o terror dos conservadores, especialmente dos puritanos mais conservadores identificados como presbiterianos" $"$ (MULLETT, 1994, p. 195), a considerar a sua própria situação em relação à Igreja da Inglaterra.

Segundo Mullett (1994), a suspensão da censura contra a imprensa durante a Guerra Civil propiciou o enriquecimento dos debates, favorecendo a expressão das opiniões radicais, como a antinomiana, por exemplo, que nega a ideia de que as leis morais mantêm a união do cristão com Deus. Embora muitas dessas opiniões funcionassem mais no plano teórico das correntes dissidentes mais extremas, a uniformidade religiosa começou a dissolver-se em uma sociedade cada vez mais diversa. Após rígida opressão, os dissidentes ainda eram proibidos de ingressar na universidade ou de participar na política; contudo, o Ato de Tolerância de 1689 ao menos deu direito de existência às seitas radicais (MULLETT, 1994).

\footnotetext{
5 "The 'Brownists, Anabaptists, Arians, Thraskists, Familists, Sensualists, Antinomians and others' (...) were the terror of conservatives, and especially of the more conservative Puritans labeled Presbyterians".
} 
Se a luta em relação à religião oficial alcançava uma situação menos complicada, os dissidentes voltavam-se para um novo problema: a autoridade dos líderes das novas igrejas. Algumas tendências dissidentes sequer formavam instituição organizada, a exemplo dos Seekers e dos Ranters; já outras, como os batistas, acabaram por configurar uma estrutura que permitia a senhores, homens, instruídos, usarem a Bíblia como instrumento em favor de elites para a dominação dos iletrados. Muitos dos insatisfeitos com a tirania do pastor e da Bíblia viram a solução no quakerismo, seita na qual a Bíblia dividia a autoridade com outras fontes de inspiração, incluindo a iluminação direta que qualquer homem ou mulher poderia receber (MULLETT, 1994).

Os grupos dissidentes, que estabilizaram seu número de seguidores por volta de 1720 - totalizavam um terço de um milhão de fiéis, pouco mais de seis por cento do total da população inglesa -, mantiveram "sua vitalidade não apenas na consolidação numérica e em confiança política, mas também em criatividade devocional"6 (MULLETT, 1994, p. 209). Esta vitalidade, no entanto, foi abalada pela era da razão - que coincide com a época na qual Blake produziu seus livros proféticos.

Desde cedo, Blake esteve em contato com os discursos dissidentes, que ajudaram a formar o seu repertório cultural. Situar Blake em uma seita ou escola certamente não seria um procedimento adequado. Contudo, é possível situá-lo em uma tendência, embora esta não seja uma tarefa simples e incontroversa. Não por acaso, Jon Mee (1992, p. 05) usa o termo "bricolagem", tomado de Lévi-Strauss, para referir-se à obra do poeta: "ele inspirou-se em discursos díspares para criar uma 'bricolagem' que tem características em comum com a obra de Spence, Paine e outros radicais"'?

Este variado repertório que se percebe na obra de Blake não deve surpreender em alguém que teve uma educação informal e ligada a uma tradição marcada pela pluralidade. Assim, Blake pode ser visto como figura típica do seu tempo (MCCALMAN, 1991, p. 11); eram muitos os contemporâneos que produziam formas textuais diferentes de um padrão estabelecido na tradição de Cambridge e Oxford. E não era, de forma alguma, o único a considerar-se "profeta" e chamar seus poemas de "profecias" no período das revoluções ${ }^{8}$. Muitos outros também publicaram profecias - correndo o risco de serem

\footnotetext{
6 “ $(. .$.$) the dissident churches were exhibiting vitality not just in numerical consolidation and$ political confidence but also in devotional creativity".

7 “ "(...) he drew on disparate discourses to create a bricolage which has features in common with the work of Spence, Paine, and other radicals". Mee está contrastando o pensamento do autor de Rights of Man ao de Thomas Spence, autor de Pigs 'Meat.

8 "Profecia", nesse caso, não tem o sentido de previsão do futuro. Ian Balfour discute esta questão em "The Mediated Vision: Blake, Milton, and the Lines of Prophetic Tradition" (BALFOUR, 2002). Nas palavras do crítico, "When Blake claims the prophet is one who "utters his opinion both of provate \& public matters,' he employs a sense of prophecy recalling its usage in Protestant discourse of seventeenth century and much farther back to a Pauline sense of 'prophesying.' In Jeremy Taylor's important treatise The Liberty o Prophesying (1647), for example, to 'prophesy' is synonymous with to 'speak forth' or 'to speak out' and thus has more to do with freedom of expression or sheer speaking on behalf of God" (p. 131).
} 
penalizados pelas severas leis elizabetanas - e tiveram histórias de vida bastante curiosas. Richard Brothers, por exemplo, um ex-oficial da marinha, passou a anunciar terremotos, revoluções e a queda das monarquias e, no papel de "Sobrinho de Deus", acreditava ser o guia que conduziria os hebreus à Palestina, onde reconstruiriam Jerusalém (MAKDISI, 2002, p. 20). Brothers atingiu fama nacional com a publicação de seu A Revealed Knowledge of the Prophecies and Times (MEE, 1992, p. 29). Os dois volumes deste livro, que teriam sido escritos diretamente sob a inspiração divina segundo o seu autor, geraram um acalorado debate, incluindo The Age of Revolution! (1795), escrito por um seguidor anônimo, e The Prophet of the Hebrews (1795) de Gibray, que satirizava a pretensão do "Sobrinho de Deus" (MEE, 1992, p. 23). Embora Brothers acreditasse que desempenhava uma tarefa especial - explica Mee (1994) -, ficava satisfeito com as respostas proféticas que apareciam em torno de sua obra, o que indica que ele nutria uma visão democrática do papel do profeta, de modo semelhante ao de Blake. De fato, a confiança na disponibilidade dos poderes visionários em cada indivíduo era uma realidade vivida na experiência da cultura popular da época. Como evidência disso, podem ser citadas, ainda, obras como Prophetical Extracts (1794-1795), do gravurista Garnet Terry, Wonderful Prophecies (1818), de George Turner, The Present State of Europe Compared with Ancient Prophecies (1794), de Joseph Pristley, que afirmavam a condição de profecia explicitamente nos títulos de seus textos (MEE, 1992).

Thomas Spence (1750-1814) foi outro dos vários contemporâneos de Blake que publicavam formas de pensamento radical colocando-se como profetas. Spence nasceu em uma família de artesãos profundamente religiosa. Era professor em uma escola em Newcastle quando foi convidado a dar uma palestra na Sociedade Filosófica de Newcastle, de onde foi afastado por passar a divulgar suas ideias nas ruas da cidade. Spence perdeu o emprego e seguiu para Londres, onde tentou vários tipos de trabalho no comércio (SPENCE, 1982). Tornou-se figura relativamente conhecida, alvo de zombaria, às vezes levado a sério, sendo preso em várias ocasiões por defender seu "plano de sociedade, tão de acordo com os Direitos do Homem, que até os selvagens invejariam, e desejariam tornarse membros dela" "SPENCE, 1982, p. 75).

O plano de Spence concebia uma comunidade - cujo exemplo fictício era a ilha de Spensonia - construída com base na propriedade pública da terra. A propriedade particular, segundo Spence, era a primeira causa de toda a opressão e desigualdade entre os seres humanos. A liberdade e a felicidade da humanidade estariam preservadas - ou restauradas, como uma espécie de volta ao Paraíso -, então, se a terra fosse patrimônio público:

\footnotetext{
9 "Such studies, Sir, as these, were what stirred me up with an irresistible enthusiasm, to lay before the world a plan of society, so consonant to the Rights of Man, that even savages should envy, and wish to become members thereof".
} 
Então o sr. acredita que a vontade irracional de indivíduos arrogantes deve ser atendida, em detrimento de um povo inteiro? A propriedade particular da terra ou é justa, de acordo com a lei da natureza, ou não é. Que não é, é evidente devido às consequências não naturais e opressivas que derivam disto. Se toda tirania, e os abusos do governo, derivam somente do sistema monopolizante, ele será, é claro, a principal fonte da tirania; pesquise a história, e veja que o governo de qualquer país sempre esteve, e está, nas mãos dos proprietários de terras. Se o povo então quiser ter o governo em suas próprias mãos, deve em primeiro lugar tomar as terras em suas próprias mãos ${ }^{10}$ (SPENCE, 1982, p. 88).

De modo semelhante a Blake, Spence expressa uma religiosidade independente da religião institucionalizada. Em maior ou menor grau, os escritos desses e de outros profetas da Inglaterra do século XVIII existem a partir das heresias antinomianas do século anterior. $\mathrm{Na}$ verdade, houve um verdadeiro ressurgimento do entusiasmo popular da primeira metade do século XVII. Como evidência disso, sabe-se que John Saltmarsh não foi o único radical religioso setecentista a ser republicado na década de 1790, conforme mostra Mee (1994). Assim, o "antinomianismo de Blake era parte de um revival mais amplo que acontecia a seu redor na cultura popular de Londres” (MEE, 1994, p. 48).

$\mathrm{O}$ antinomismo ou antinomianismo, no sentido comum, pode ser identificado como postura de recusa de normas e leis; em sentido mais específico, é a posição de que "os que são salvos pela graça não têm a obrigação de observar a lei moral"11 (MULLETT, 2010, p. 14). Indo um pouco além dessa definição, pode-se dizer, com Mee (1994), que essa noção de "graça livre" - a salvação adquirida independentemente da obediência a qualquer código de lei ética ou moral - tem origem na leitura de passagens como I João 3:9: "Todo aquele que nasceu de Deus não comete pecado, / porque sua semente permanece nele; / ele não pode pecar / porque nasceu de Deus" (Bíblia de Jerusalém). Diferentes reações antinomianas podem ser relacionadas a esse texto; algumas mantêm-se no plano teórico apenas, enquanto outras encontram a convicção prática de um estado de salvação já alcançado, o que tornaria redundante a preocupação com qualquer categoria que se pudesse chamar de pecado. Para Mee, The Marriage of Heaven and Hell de Blake aproxima-se desse tipo de extremismo antinomiano. Realmente, esta é a impressão suscitada por passagens como:

\footnotetext{
10 "So you think that the unreasoning desires of wayward individuals should be complied with, to the detriment of the whole people? Private property in land, is either just, according to the law of nature, or it is not. That it is not, is evident from the unnatural and oppressive consequences flowing from it. If all tyranny, and all abuses in the government, flow only from that monopolizing system, it must, of course, be the fountain head of tyranny; search history, and see, that the government of every country ever was, and is, in the proprietors of land. If then people wish to have the government in their own hands, they must begin first, by taking the land into their own hands".

11 "those saved by grace have no obligation to observe the moral law".
} 
Porque tudo o que vive é Sagrado.

(BLAKE, 2001, p. 59)

Digo-te: nenhuma virtude pode existir sem a quebra desses dez mandamentos. Jesus era todo virtude, e agia por impulso, não por regras.

(BLAKE, 2001, p. 51)

Mee (1994, p. 44) observa que uma face mais passiva do antinomianismo leva em conta o perdão incondicional para o que ainda consideraria pecado. $O$ crítico argumenta que vem desta corrente a ênfase que as profecias maduras de Blake colocam sobre a ideia do perdão. Em Jerusalem, por exemplo, grande número de versos é dedicado à defesa do perdão incondicional:

(...) Ouvi sua voz em meu sono \& seu Anjo em meu sonho:

Dizendo, Jeová Perdoa um Débito apenas na condição de que

Será Pago? Ele Perdoa a Profanação apenas na condição de

[Pureza

Tal é o Perdão dos Deuses, as Virtudes Morais dos

Pagãos, cujas ternas Misericórdias são Crueldade. Mas a

[Salvação de Jeová

É sem Dinheiro \& sem Preço, no Perdão Contínuo dos Pecados ${ }^{12}$

(BLAKE, 2010, p. 168)

Mee ressalta o fato de a questão da "graça livre" ter produzido uma série de respostas diferentes entre os antinomianos, inclusive a de que apenas os Eleitos seriam dignos de serem salvos (opinião que Blake não compartilhava). Esta variedade de opiniões é suficiente para mostrar que o antinomianismo radical não é uma seita, mas uma tendência. Dessa tendência, como se vê, algumas características podem ser identificadas na obra de Blake, sendo uma das mais importantes a crença na superioridade do espírito sobre a presença da lei, "o que envolve uma antipatia anticlerical, aos aspectos cerimoniais e institucionais da religião" "13 uma antipatia que se estende a qualquer autoridade e leis em geral (MEE, 1994, p. 44).

A destruição da noção de autoridade percebida na atitude antinomiana é uma característica fundamental para a construção da figura do profeta no radicalismo popular inglês do século XVIII. “As Religiões de todas as Nações são derivadas das diferentes recepções de cada Nação para o Gênio Poético, que é conhecido em todo lugar como o Espírito da Profecia"14 (ERDMAN, 1988, p. 01), diz Blake em All Religions are One (1788). Nessa passagem, repetida de

\footnotetext{
${ }^{12}$ A discussão sobre o perdão é, aqui, ilustrada com o episódio do anúncio do anjo a José sobre o nascimento de Jesus (Mateus, 1). Na leitura de Blake, o pecado moral de Maria existiu, embora tenha sido negado ou anulado pelo perdão de José (ver, por exemplo, STURROCK, 1992;

DAMON, 1988, p. 264).

13 “(...) an anticlerical antipathy to the ceremonial and institutional aspects of religion".

14 "The Religions of all Nations are derived from each Nation's different reception of the Poetic Genius, which is every where call'd the Spirit of Prophecy".
} 
diferentes maneiras ao longo da sua obra, o poeta iguala a validade de qualquer variedade do impulso religioso, dando o sentido de que nenhuma religião, como expressão criativa, poderia reclamar para si a superioridade sobre as outras, a ponto de fazer-se instrumento de dominação. Da mesma forma, este tipo de discurso legitima a possibilidade de qualquer pessoa exercitar sua habilidade profética, como característica divina inerente a toda a humanidade.

\section{Referências}

BALFOUR, Ian. The Rhetoric of Romantic Prophecy. Stanford: Stanford University Press, 2002.

BENTLEY JR, Gerald Eades. The Stranger from Paradise - A Biography of William Blake. New Heaven / London: Yale University Press, 2001.

Bíblia de Jerusalém. São Paulo: Paulus, 2002.

BLAKE, William. Jerusalém. Tradução de Saulo Alencastre. São Paulo: Hedra, 2010.

. O Matrimônio do Céu e do Inferno / O Livro de Thel. Tradução de José Antônio Arantes. $4^{a}$ edição. São Paulo: Iluminuras, 2001.

DAMON, Samuel Foster. A Blake Dictionary - The Ideas and Symbols of William Blake. Revised Edition with a new foreword and annotated bibliography by Morris Eaves. Hanover/ London: University Press of New England, 1988.

ERDMAN, David V. The Complete Poetry \& Prose of William Blake. Newly revised edition. New York / London / Toronto / Sydney / Auckland: Anchor Books, 1988.

FRYE, Northrop. Fearful Symmetry: a study of William Blake. $10^{\text {th }}$ printing. Princeton: Princeton University Press, 1990.

MAKDISI, Saree. William Blake and the Impossible History of the 1790s. Chicago / London: The University of Chicago Press, 2003.

MCCALMAN, Iain. Introduction. In: (ed.). The Horrors of Slavery and Other Writings by Robert Wedderburn. New York: Marcus Wiener, 1991.

MEE, Jon. Blake's politics in history. In: Eaves, Morris (ed.). The Cambridge Companion to William Blake. Cambridge: Cambridge University Press, 2003.

. Dangerous Enthusiasm - William Blake and the Culture of Radicalism in the 1790s. New York: Oxford University Press, 1992. 
. Is there an Antinomian in the House? William Blake and the After-Life of a Heresy. In: CLARK, Steve \& DAVID, Worral (ed.). Historicizing Blake. New York: St. Martin's Press, 1994.

MULLETT, Michael. Historical Dictionary of the Reformation and CounterReformation. Lanham/Toronto/Plymouth: The Scarecrow Press, 2010.

. Radical Sects and Dissenting Churches, 1600-1750. In: GILLEY, Sheridan \& SHEILS, W. J,. A History of Religion in Britain. Practice and Belief from Pre-Roman Times to the Present. Cambridge/Oxford: Blackwell, 1994.

SMITH, Nigel. Perfection Proclaimed - Language and Literature in English Radical Religion 1640-1660. New York: Oxford University Press, 1989.

SPENCE, Thomas. Pigs' Meat - The Selected Writings of Thomas Spence, Radical and Pioneer Land Reformer. Nottingham: Russell Press, 1982.

STURROCK, Jane. Blake and the Women of the Bible. Journal of Literature \& Theology, vol. 6. $\mathrm{n}^{\mathrm{o}}$ 1. Oxford: Oxford University Press, 1992.

Juliana Steil JulianaSteil@gmail.com

Recebido em: 13 ago. 2018 Aceito em: 22 nov. 2018 Publicado em: 29 dez. 2018 